\title{
O ESTADO NUTRICIONAL DAS PLANTAS MATRIZES E O USO DE AIB INTERFEREM NO ENRAIZAMENTO DE ESTACAS DE Prunus SPP.
}

\author{
Gabriela Gerhardt da Rosa ${ }^{1}$, Ilisandra Zanandrea ${ }^{2}$, Newton Alex Mayer ${ }^{3}$, Valmor João \\ Bianchi $^{4}$
}

\footnotetext{
${ }^{1}$ Engenheira Agrônoma, Doutoranda do PPG em Fisiologia Vegetal, Universidade Federal de Pelotas (UFPel), Pelotas, Rio Grande do Sul, e-mail birela89@gmail.com.

${ }^{2}$ Biologa, Doutora, Professora adjunta do Departamento de Biologia, Universidade Federal do Maranhão (UFMA), São Luís, Maranhão, e-mail dandajs@gmail.com.

${ }^{3}$ Engenheiro Agrônomo, Doutor, Pesquisador da Embrapa Clima Temperado, Embrapa Clima Temperado, Pelotas, Rio Grande do Sul, e-mail alex.mayer@embrapa.br.

${ }^{4}$ Engenheiro Agrônomo, Doutor, Professor Associado do Departamento de Botânica, Universidade Federal de Pelotas (UFPel), Pelotas, Rio Grande do Sul, e-mail valmorjb@yahoo.com.
}

RESUMO: O objetivo deste trabalho foi avaliar o efeito do ácido indolilbutírico (AIB) no enraizamento adventício de estacas herbáceas e semi-lenhosas de porta-enxertos de pessegueiro, bem como a possível relação com o teor de nutrientes do material propagativo utilizado. Estacas oriundas de ramos herbáceos e semi-lenhosos de três genótipos de Prunus spp. foram preparadas com $15 \mathrm{~cm}$ de comprimento, mantendo-se um par de folhas inteiras na parte apical das mesmas. Para os três genótipos foram utilizados dois tratamentos: controle ( 0 $\mathrm{mg} \mathrm{L}^{-1}$ de AIB) e imersão da base da estaca em solução de AIB (2.000 $\left.\mathrm{mg} \mathrm{L}^{-1}\right)$. As estacas foram acondicionadas em caixa contendo vermiculita fina e mantidas sob nebulização intermitente por 50 dias. O enraizamento das estacas herbáceas tratadas com AIB foi superior a $83 \%$ para todas as cultivares, enquanto que nas semi-lenhosas foi de $90 \%$ para 'Genovesa' e 'Marianna 2624', e de apenas 30\% para 'Flordaguard'. 'Genovesa' apresentou o maior número, comprimento e massa seca das raízes em todos os tratamentos e em ambos os tipos de estacas, o que pode estar relacionado com às concentrações de nutrientes essenciais nos seus ramos, como cálcio, magnésio, nitrogênio, fósforo e zinco. Os resultados obtidos comprovam que o fator genético e a composição nutricional adequada dos tecidos da planta matriz tem relevância no enraizamento, entretanto, o uso do AIB demonstrou ser essencial para se obter sucesso no enraizamento adventício e na qualidade das raízes formadas nos três genótipos estudados.

Palavras-chave: Ácido indolilbutírico. Enraizamento. Nutrientes. Prunus persica. P. salicina.

\section{THE NUTRITIONAL STATUS OF THE MOTHER TREES AND THE USE OF AIB INTERFERE IN THE ROOTING CUTTINGS OF Prunus SPP.}

\begin{abstract}
The objective of this study was to evaluate the effect of the use of IBA on rooting of semi-hardwood and softwood cuttings of peach rootstocks and evaluate the adventitious rooting coupled with the nutrient content of propagation material used. Prepared
\end{abstract}

Cultura Agronômica, Ilha Solteira, v.26, n.2, p.174-190, 2017 
cuttings derived from herbaceous and semi-hardwood cultivars of Prunus spp. with $15 \mathrm{~cm}$ long, maintaining a pair of whole leaves in the apical part of the same. Both treatments were used: control and immersion of the cuttings base in IBA solution $\left(2000 \mathrm{mg} \mathrm{L}^{-1}\right)$. Then the cuttings were placed in boxes containing vermiculite and kept under intermittent mist for 50 days. The rooting of softwood cuttings treated with IBA was above $80 \%$ for all cultivars, while in semi-hardwoody, was $90 \%$ for 'Genovese' and 'Marianna 2629', and only $30 \%$ for 'Flordaguard'. 'Genovese' had the largest number, length and dry weight of roots in all treatments and in both types of cuttings which can be connected to the low differential concentration of some essential nutrients such as calcium, magnesium, nitrogen, phosphorus and zinc. The results show that the genetic factor and the appropriate nutrient composition of the cuttings mother plant tissue has relevance in rooting. The use of IBA proved to be essential for success in adventitious rooting and the quality of the formed roots in the three genotypes studied.

Key words: Indolebutyric acid. Rooting. Nutrients. Prunus persica. P. salicina.

\section{INTRODUÇÃO}

A utilização de porta-enxertos na produção de frutíferas do gênero Prunus, possibilita o cultivo destas em locais em que as condições edafoclimáticas sejam limitantes ao desempenho produtivo do pomar (SCHIMITZ et al., 2012). Ainda, para uma melhor produção, preconiza-se a manutenção das características genéticas de cada cultivar e esta garantia é assegurada, principalmente, através da propagação clonal, utilizando a técnica de estaquia. Esta tem demonstrado ser vantajosa, pois permite a propagação de um grande número de plantas em curto espaço de tempo (FRANZON et al., 2010).

Entretanto, sabe-se que muitas espécies e cultivares de Prunus spp. são difíceis de enraizar e essa dificuldade é ainda um dos principais obstáculos na utilização da propagação clonal a nível comercial (CANLI; BOZKURT, 2009; DUVAL et al., 2013). Para contornar esse problema e visando maximizar a porcentagem de enraizamento das estacas, utiliza-se a aplicação exógena de reguladores vegetais, como as auxinas, que tem como principal representante o ácido indolilbutírico (AIB). O AIB é a principal auxina utilizada no enraizamento de estacas, devido ao menor custo e baixo efeito fitotóxico para a maioria das espécies vegetais (AGUIAR et al., 2005; TOFANELLI et al., 2002).

Porém, o enraizamento de estacas não ocorre apenas com o uso de reguladores vegetais, existe uma complexa gama de fatores envolvidos, como a nutrição do material vegetal utilizado. De acordo com Cunha et al. (2009), a mobilização de nutrientes minerais durante a iniciação radicular é diferente daquela que ocorre durante o crescimento e desenvolvimento da raiz, sendo mais acentuada nesta última fase, sugerindo que a iniciação radicular é altamente dependente dos níveis iniciais de nutrientes presentes no tecido vegetal.

Cultura Agronômica, Ilha Solteira, v.26, n.2, p.174-190, 2017 
Embora, a nutrição mineral e o enraizamento de estacas estejam intimamente relacionados, poucos estudos têm sido realizados relacionando o efeito da nutrição dos ramos sobre o enraizamento de espécies de Prunus spp com ou sem AIB. Deste modo, buscou-se avaliar o efeito da nutrição das plantas matrizes e de doses de AIB no enraizamento de estacas oriundas de ramos herbáceos e semi-lenhosos de pessegueiro.

\section{MATERIAL E MÉTODOS}

O trabalho foi conduzido em estufa agrícola não climatizada e equipada com câmara de nebulização intermitente, pertencente à EMBRAPA Clima Temperado. O material vegetal foi coletado de plantas matrizes implantadas na "Coleção Porta-enxertos de Prunus", mantida em condição de campo sem irrigação, na Sede da mesma instituição.

O material vegetal foi colhido dos cultivares Flordaguard (Prunus persica L. Batsch), Marianna 2624 ( $P$. cerasifera x P. munsoniana) e Genovesa ( $P$. salicina Earh). As plantas matrizes destes cultivares foram submetidas à poda drástica no inverno de 2012, cortando-se todas os ramos principais a uma altura aproximada de $1,1 \mathrm{~m}$, objetivando estimular intensa e vigorosa brotação na primavera, padronizando-se os ramos quanto à idade.

Dois experimentos foram realizados: a) com estacas herbáceas, instalado em novembro de 2012, (Experimento 1); e b) com estacas semi-lenhosas, em janeiro de 2013 (Experimento 2). Após a coleta, os ramos foram levados imediatamente para câmara de nebulização intermitente, a qual se encontra instalada no interior de uma estufa agrícola ( 24 x 8m) tipo arco, com teto de polietileno e laterais com tela antiafídeos e sobre os aspersores de nebulização intermitente, contém uma tela refletora luminet, para reduzir a radiação solar.

As estacas possuíam diâmetro médio de $7 \mathrm{~mm}$ e foram preparadas com $15 \mathrm{~cm}$ de comprimento, mantendo-se dois pares de folhas inteiras na porção apical. A base foi cortada transversalmente (imediatamente abaixo de um nó ou gema) e o ápice em bisel. Na base da estaca foram feitas duas lesões opostas $( \pm 3 \mathrm{~cm})$, a fim de expor o câmbio vascular. Metade das estacas de cada cultivar foi tratada com solução de ácido indolilbutírico (AIB) por 10 segundos (2.000 $\left.\mathrm{mg} \mathrm{L}^{-1}\right)$, preparada na proporção 3:1 (v/v, água e álcool, respectivamente) e a outra metade tratada com solução controle, composta de água destilada e álcool, na proporção 3:1 (v/v), também por 10 segundos. Em seguida, as estacas foram acondicionadas em caixas plásticas contendo vermiculita de granulometria fina e mantidas sob sistema de nebulização intermitente, controlado por temporizador, programado para nebulizar durante 10 segundos, 24 horas por dia, com intervalos de três minutos, durante todo o período experimental.

Ambos os experimentos foram avaliados aos 50 dias após a instalação, mensurando-se as seguintes variáveis: número de folhas originais por estaca, porcentagem de estacas com permanência de folhas (\%), a porcentagem de estacas brotadas (\%), comprimento médio da maior brotação $(\mathrm{cm})$, massa seca de brotações $(\mathrm{g})$, porcentagem de estacas vivas $(\%)$, porcentagem de estacas enraizadas (\%), número médio de raízes por estaca, comprimento 
médio das três maiores raízes $(\mathrm{cm})$, massa seca de raízes $(\mathrm{g})$. A massa seca das brotações e das raízes foi obtida através da secagem em estufa, à temperatura de $50^{\circ} \mathrm{C}$, até massa constante.

Amostras compostas por folhas mais segmentos de estacas de cada cultivar foram coletadas durante o preparo das mesmas para análises químicas de macronutrientes [nitrogênio $(\mathrm{N})$, fósforo $(\mathrm{P})$, potássio $(\mathrm{K})$, magnésio $(\mathrm{Mg})$ e cálcio $(\mathrm{Ca})$, expressas em \%] e

micronutrientes [ferro $(\mathrm{Fe})$, manganês $(\mathrm{Mn})$ e zinco $(\mathrm{Zn})$, expressas em $\mathrm{mg} \mathrm{kg}^{-1}$ ]. Para as análises, as amostras foram seccionadas em porções menores, acondicionadas em sacos de papel pardo e secas em estufa de circulação forçada de ar, a $50^{\circ} \mathrm{C}$ até massa constante. Quatro amostras de cada cultivar e tipo de estaca foram moídas em moinho e destas foram separadas duas subamostras para análise de macro e micronutrientes, que foi realizada na Central Analítica do Laboratório de Fertilidade do Solo da EMBRAPA Clima Temperado, que está integrada à Rede Oficial de Laboratórios de Análise de Solo e de Tecido Vegetal do RS e de SC (CQFS-RS/SC, 2016). Os resultados das análises foram interpretados com base nos padrões do Manual de adubação e calagem para RS e SC (CQFS-RS/SC, 2016).

O delineamento experimental utilizado foi o inteiramente casualizado, em esquema fatorial $3 \times 2$ (três cultivares e duas doses de AIB) sendo, Experimento 1 (estaca herbáceas) e o Experimento 2 (estacas semi-lenhosas) avaliados independentemente. Cada tratamento foi composto por quatro repetições, sendo a parcela composta por 15 estacas. Realizou-se a análise de variância dos dados, e quando significativo realizou-se a comparação das médias pelo teste Tukey a $5 \%$ de probabilidade de erro, utilizando o software Sisvar (FERREIRA, 2008).

\section{RESULTADOS E DISCUSSÃO}

\section{Estacas Herbáceas}

Os dados referentes ao experimento 1 (estacas herbáceas) são apresentados nas tabelas $1,2,3,4,5$ e 6 pelas quais pode ser observada a interação entre os fatores porcentagem de estacas enraizadas e número médio de raízes por estaca (Tabela 1), comprimento médio das três maiores raízes e massa seca das raízes (Tabela 2). Para as variáveis número de folhas originais por estaca, porcentagem de estacas com folhas originais e porcentagem total de estacas vivas verificou-se efeito significativo apenas para o fator cultivar (Tabela 3). Ainda, observpu-se interação entre os fatores porcentagem de estacas com brotações, comprimento e massa seca das brotações (Tabela 4).

Para a porcentagem de estacas enraizadas verificou-se efeito significativo da aplicação de AIB para 'Flordaguard' e 'Marianna 2624' (90\% e 83,33\%, respectivamente) em relação ao tratamento controle ( $30 \%$ e $71,66 \%$, respectivamente), enquanto que para 'Genovesa' a porcentagem de estacas enraizadas foi superior a 94\%, independente da aplicação de AIB (Tabela 1). Entretanto, das estacas tratadas com AIB, as de 'Genovesa' tiveram a maior porcentagem de enraizamento (98,33\%), diferindo apenas de 'Marianna 2624' (83,33\%).

Cultura Agronômica, Ilha Solteira, v.26, n.2, p.174-190, 2017 
Dentre as estacas não tratadas com AIB, as de 'Genovesa' apresentaram maior porcentagem de enraizamento (94,43\%) em relação à 'Marianna 2624' e 'Flordaguard' (71,66\% e 30\%, respectivamente).

Nas três cultivares avaliadas, o maior número médio de raízes por estaca foi registrado no tratamento com AIB, sendo $71 \%$ maior quando comparado ao controle (Tabela 1). Verificou-se também que nas estacas tratadas com AIB, as de 'Genovesa' apresentaram o maior número médio de raízes por estaca $(44,70)$ (Tabela 1). No tratamento controle, 'Genovesa' e 'Marianna 2624' (12,32 e 9,80 raízes, respectivamente) não diferiram entre si, mas foram superiores a 'Flordaguard' $(1,69)$.

Tabela 1. Porcentagem de estacas enraizadas (EE), número médio de raízes por estaca (RE), em estacas herbáceas tratadas $\left(2000 \mathrm{mg} \mathrm{L}^{-1}\right)$ e não tratadas com ácido indolilbutírico (AIB) de três cultivares de Prunus spp. UFPEL, 2014.

\begin{tabular}{|c|c|c|c|c|}
\hline \multirow[t]{2}{*}{ Porta-enxerto } & \multicolumn{2}{|c|}{ EE $(\%)$} & \multicolumn{2}{|c|}{$\operatorname{RE}\left(n^{o}\right)$} \\
\hline & $\operatorname{com} \mathrm{AIB}$ & sem AIB & com AIB & sem AIB \\
\hline 'Flordaguard' & $90,00 \mathrm{abA}$ & $30,00 \mathrm{cB}$ & $12,18 \mathrm{cA}$ & $1,69 \mathrm{bB}$ \\
\hline 'Genovesa' & $98,33 \mathrm{aA}$ & $94,43 \mathrm{aA}$ & $44,70 \mathrm{aA}$ & $12,32 \mathrm{aB}$ \\
\hline 'Marianna 2624' & $83,33 \mathrm{bA}$ & $71,66 \mathrm{bB}$ & $24,19 \mathrm{bA}$ & $9,80 \mathrm{aB}$ \\
\hline Média & 90,53 & 65,36 & 27,30 & 7,93 \\
\hline $\mathrm{CV}(\%)$ & \multicolumn{2}{|c|}{7,00} & \multicolumn{2}{|c|}{18,02} \\
\hline
\end{tabular}

Médias seguidas pela mesma letra minúscula na coluna e maiúscula na linha, não diferem entre si pelo teste Tukey $(\mathrm{p}<0,05)$.

Tabela 2. Comprimento médio das três maiores raízes (CMR) e massa seca das raízes (MSR) em estacas herbáceas tratadas $\left(2000 \mathrm{mg} \mathrm{L}^{-1}\right)$ e não tratadas com ácido indolilbutírico (AIB) de três cultivares de Prunus spp. UFPEL, 2014.

\begin{tabular}{|c|c|c|c|c|}
\hline \multirow[t]{2}{*}{ Porta-enxerto } & \multicolumn{2}{|c|}{$\mathrm{CMR}(\mathrm{cm})$} & \multicolumn{2}{|c|}{$\operatorname{MSR}(\mathrm{g})$} \\
\hline & com AIB & sem AIB & com AIB & sem AIB \\
\hline 'Flordaguard' & $13,75 \mathrm{aA}$ & $11,26 \mathrm{abB}$ & $2,57 \mathrm{abA}$ & $0,33 \mathrm{bB}$ \\
\hline 'Genovesa' & $11,02 \mathrm{bA}$ & $12,51 \mathrm{aA}$ & $3,23 \mathrm{aA}$ & $2,47 \mathrm{aA}$ \\
\hline 'Marianna 2624' & $11,12 \mathrm{bA}$ & $9,19 \mathrm{bB}$ & $1,56 \mathrm{bA}$ & $1,19 \mathrm{bA}$ \\
\hline Média & 11,96 & 14,97 & 2,45 & 1,33 \\
\hline $\mathrm{CV}(\%)$ & \multicolumn{2}{|c|}{10,98} & \multicolumn{2}{|c|}{33,12} \\
\hline
\end{tabular}

Médias seguidas pela mesma letra minúscula na coluna e maiúscula na linha, não diferem entre si pelo teste Tukey $(\mathrm{p}<0,05)$.

O comprimento médio das três maiores raízes foi maior nas estacas de 'Flordaguard' e 'Marianna 2624' tratadas com AIB (13,75 cm e 11,12 cm, respectivamente), em relação ao tratamento controle, enquanto que para 'Genovesa' não houve diferença significativa com e sem aplicação de AIB (Tabela 2). Comparando os efeitos da aplicação do AIB, 'Flordaguard' foi superior as demais cultivares, porém no tratamento controle, sem AIB, 'Genovesa' apresentou maior comprimento médio de raízes somente em relação à 'Marianna 2624' (Tabela 2). Para massa seca das raízes, 'Genovesa' apresentou a maior média de massa seca

Cultura Agronômica, Ilha Solteira, v.26, n.2, p.174-190, 2017 
das raízes $(2,47 \mathrm{~g})$ para estacas não tratadas com AIB, enquanto nas estacas tradadas com AIB foi superior apenas em relação à 'Marianna 2624' (Tabela 2).

Avaliando apenas o efeito do fator cultivar observou-se que nas três cultivares estudadas a porcentagem de estacas vivas foi superior a 93\% (Tabela 3). Resultado similar foi obtido para a porcentagem de estacas com folhas originais, onde 'Genovesa' (100\%) não diferiu de 'Flordaguard', mas foi superior à 'Marianna 2624' (89,20\%). Para o número de folhas originais por estaca, 'Flordaguard' foi a cultivar que apresentou a menor abscisão foliar, sendo superior as demais cultivares que não diferiram entre si (Tabela 3). Para estas três variáveis não ocorreu diferenças significativas em relação à aplicação ou não de AIB nas estacas.

Tabela 3. Porcentagem total de estacas vivas (TEV), porcentagem de estacas com permanência de folhas (ECF) e número de folhas originais por estaca (NFO), em estacas herbáceas de três cultivares de Prunus spp. tratadas ou não com ácido indolilbutírico (AIB). UFPEL, 2014.

\begin{tabular}{llll}
\hline Porta-enxerto & TEV $(\boldsymbol{\%})$ & ECF $(\boldsymbol{\%})$ & NFO $\left(\mathbf{N}^{\mathbf{}}\right)$ \\
\hline 'Flordaguard' & $98,33 \mathrm{ab}$ & $95,00 \mathrm{ab}$ & $3,20 \mathrm{a}$ \\
'Genovesa' & $100,0 \mathrm{a}$ & $100,0 \mathrm{a}$ & $2,61 \mathrm{~b}$ \\
'Marianna 2624' & $93,33 \mathrm{~b}$ & $89,20 \mathrm{~b}$ & $2,21 \mathrm{~b}$ \\
\hline Tratamento & TEV $(\boldsymbol{\%})$ & ECF $(\boldsymbol{\%})$ & NFO (N) \\
\hline Com AIB & $96,66 \mathrm{NS}$ & $94,00 \mathrm{NS}$ & $2,74 \mathrm{NS}$ \\
Sem AIB & $97,77 \mathrm{NS}$ & $95,5 \mathrm{NS}$ & $2,60 \mathrm{NS}$ \\
\hline MEDIA & 97,22 & 94,72 & 2,67 \\
\hline CV $(\boldsymbol{\%})$ & 4,85 & 7,18 & 13,93 \\
\hline
\end{tabular}

Médias seguidas pela mesma letra, na coluna, não diferem entre si pelo teste Tukey $(\alpha<0,05)$. NS= Não Significativo.

Tabela 4. Porcentagem de estacas brotadas (ECB), comprimento médio da maior brotação (CMB) e massa seca das brotações (MSB) em estacas herbáceas de três cultivares de Prunus spp. tratadas ou não com ácido indolilbutírico (AIB). UFPEL, 2014.

\begin{tabular}{llccccc}
\hline \multirow{2}{*}{ Porta-enxerto } & \multicolumn{2}{c}{ ECB (\%) } & \multicolumn{2}{c}{ CMB $(\mathbf{c m})$} & \multicolumn{2}{c}{ MSB $(\mathbf{g})$} \\
\cline { 2 - 7 } & Com & Sem & Com & Sem & Com & Sem \\
& AIB & AIB & AIB & AIB & AIB & AIB \\
\hline 'Flordaguard' & $26,66 \mathrm{bA}$ & $28,33 \mathrm{cA}$ & $1,35 \mathrm{bB}$ & $3,39 \mathrm{cA}$ & $0,24 \mathrm{cA}$ & $0,76 \mathrm{bA}$ \\
'Genovesa' & $88,33 \mathrm{aA}$ & $56,66 \mathrm{bB}$ & $9,44 \mathrm{aA}$ & $6,37 \mathrm{bB}$ & $3,57 \mathrm{bA}$ & $0,90 \mathrm{bB}$ \\
'Marianna 2624' & $96,66 \mathrm{aA}$ & $90,00 \mathrm{aA}$ & $9,95 \mathrm{aA}$ & $10,60 \mathrm{aA}$ & $4,72 \mathrm{aA}$ & $4,20 \mathrm{aA}$ \\
\hline MEDIA & 70,55 & 58,33 & 6,91 & 4,82 & 7,72 & 1,95 \\
\hline CV(\%) & \multicolumn{2}{c}{13,02} & & 12,33 & & 18,09 \\
\hline
\end{tabular}

Médias seguidas pela mesma letra minúscula na coluna e maiúscula na linha, não diferem entre si pelo teste Tukey $(\mathrm{p}<0,05)$.

Em relação à porcentagem de estacas com brotações, 'Marianna 2624' e 'Genovesa' não apresentaram diferença quando tratadas com AIB, sendo superior a 'Flordaguard', porém no tratamento sem AIB 'Mariana 2624' apresentou o maior percentual de estacas com brotação 
(90\%), seguido por 'Genovesa' e 'Flordaguard' havendo diferença entre as três cultivares. Entretanto, para o fator cultivar, 'Marianna 2624' destacou-se das demais com 96,66\% e 90,00\% das estacas brotadas, com e sem o uso de AIB, respectivamente (Tabela 4). O comprimento médio das brotações nas estacas de 'Marianna 2624' e 'Genovesa' não diferiram entre si, quando estas foram tratadas com AIB (9,95 e 9,44 cm, respectivamente), sendo $86 \%$ maiores que na cv. 'Flordaguard' (Tabela 4). No entanto, sem AIB, 'Marianna 2624' apresentou os maiores brotos $(10,60 \mathrm{~cm})$ e a maior massa seca (média de 4,20g) (Tabela 4).

Tabela 5. Valores de micronutrientes de folhas e estacas de porta-enxertos não tratadas com ácido indolilbutírico de três cultivares de Prunus spp. UFPEL, 2014.

\begin{tabular}{|c|c|c|c|c|c|}
\hline \multirow[t]{2}{*}{ Porta-enxerto } & & $\mathbf{F e}$ & Mn & & Zn \\
\hline & & \multicolumn{4}{|c|}{$\left(\mathrm{mg} \mathrm{kg}^{-1}\right)$} \\
\hline & & \multicolumn{4}{|c|}{ Estacas Herbáceas } \\
\hline \multicolumn{2}{|l|}{ 'Flordaguard' } & $81,41 * *$ & $41,35 * * *$ & & $11,91 * *$ \\
\hline \multicolumn{2}{|l|}{ 'Genovesa' } & $109,53 * * *$ & $54,33 * * *$ & & $17,50 * *$ \\
\hline \multicolumn{2}{|l|}{ 'Marianna 2624' } & $40,60 *$ & $29,30 * *$ & & $17,16^{* *}$ \\
\hline \multicolumn{2}{|l|}{ Média } & 77,18 & 41,66 & & 15,52 \\
\hline & & \multicolumn{4}{|c|}{ Estacas Semi-lenhosas } \\
\hline \multicolumn{2}{|l|}{ 'Flordaguard' } & $73,89 * *$ & $44,83 * *$ & & $12,11 * *$ \\
\hline \multicolumn{2}{|l|}{ 'Genovesa' } & $64,65 * *$ & $56,87 * * *$ & & $9,97 *$ \\
\hline \multicolumn{2}{|l|}{ 'Marianna 2624' } & $32,41 *$ & $27,16 * *$ & & $10,50 * *$ \\
\hline \multicolumn{2}{|l|}{ Média } & 56,98 & 42,95 & & 10,86 \\
\hline \multicolumn{6}{|c|}{$\begin{array}{l}\text { Médias seguidas pelos símbolos } *, * *, * * *, * * * * \text { representam teores insuficientes, abaixo do normal, norm } \\
\text { acima do normal de nutrientes nos tecidos das plantas, respectivamente. }\end{array}$} \\
\hline \multicolumn{6}{|c|}{$\begin{array}{l}\text { Tabela 6. Valores de macro e micronutrientes de folhas e estacas de porta-enxertos } \\
\text { tratadas com ácido indolilbutírico de três cultivares de Prunus spp. UFPEL, } 2014 \text {. }\end{array}$} \\
\hline \multirow[t]{3}{*}{ Porta-enxerto } & $\mathbf{N}$ & $\mathbf{P}$ & $\mathbf{K}$ & $\mathbf{C a}$ & Mg \\
\hline & & \multicolumn{4}{|c|}{$(\%)$} \\
\hline & \multicolumn{5}{|c|}{ Estacas Herbáceas } \\
\hline 'Flordaguard' & $1,47 *$ & $0,15 * * *$ & $2,01 * * *$ & $0,35 *$ & $0,09 *$ \\
\hline 'Genovesa' & $1,62 *$ & $0,14 * *$ & $2,11 * * * *$ & $0,30 *$ & $0,11^{*}$ \\
\hline 'Marianna 2624' & $1,18^{*}$ & $0,16 * * *$ & $2,08 * * * *$ & $0,19 *$ & $0,09 *$ \\
\hline \multirow[t]{2}{*}{ Média } & 1,42 & 0,15 & 2,06 & 0,28 & 0,09 \\
\hline & \multicolumn{5}{|c|}{ Estacas Semi-lenhosas } \\
\hline 'Flordaguard' & $1,38^{*}$ & $0,22 * * *$ & $1,71 * *$ & $0,43 *$ & $0,11 *$ \\
\hline 'Genovesa' & $1,29 *$ & $0,14 * *$ & $1,73 * * *$ & $0,28 *$ & $0,10^{*}$ \\
\hline 'Marianna 2624' & $0,93^{*}$ & $0,16^{* * *}$ & $2,03 * * *$ & $0,19 *$ & $0,06^{*}$ \\
\hline Média & 1,20 & 0,17 & 1,82 & 0,30 & 0,09 \\
\hline
\end{tabular}

Médias seguidas pelos símbolos *,**,***,**** representam teores insuficientes, abaixo do normal, normal e acima do normal de nutrientes nos tecidos das plantas, respectivamente.

Cultura Agronômica, Ilha Solteira, v.26, n.2, p.174-190, 2017 
Pela interpretação dos dados das análises de macro e micronutrientes contidos nas amostras das estacas herbáceas (Tabela 5 e 6) verificou-se que, nos ramos das três cultivares, os teores de $\mathrm{Ca}, \mathrm{Mg}$ e $\mathrm{N}$ estavam em concentrações considerados insuficientes para os padrões da cultura do pessegueiro. Além desses elementos, verificou-se que os teores de Fe e $\mathrm{Zn}$ também estavam abaixo do normal na cv. Flordaguard. Para 'Genovesa', P e Zn estavam abaixo do normal. A cv. Marianna 2624 apresentou concentração abaixo do normal para Zn, sendo que Fe apresentou insuficiência.

\section{Estaca semi-lenhosas}

Os dados referentes ao experimento 2 (estacas semi-lenhosas) estão apresentados nas tabelas 5, 6, 7, 8 e 9. Verificou-se interação entre os fatores nas variáveis porcentagem de estacas com brotações, porcentagem de estacas enraizadas, porcentagem de estacas vivas, número de raízes por estaca e comprimento médio das três maiores raízes. O número de folhas originais por estaca, porcentagem de estacas com permanência de folhas por estaca, comprimento médio das brotações e massa seca das brotações apresentaram efeito significativo apenas para o fator cultivar. A variável massa seca de raízes apresentou efeito significativo apenas para o uso de AIB.

Com a aplicação de AIB obteve-se maior porcentagem média de estacas semi-lenhosas enraizadas para 'Flordaguard' e 'Genovesa' (66,50\% e 94,75\%, respectivamente) em relação ao tratamento controle $(6,15 \%$ e $52 \%$, respectivamente), enquanto que para 'Marianna 2624' a porcentagem de estacas enraizadas não diferiu em ambos os tratamentos (Tabela 7). Considerando somente o tratamento sem aplicação de AIB, 'Marianna 2624' apresentou maior porcentagem de estacas enraizadas $(71,66 \%)$ em relação à 'Genovesa' e 'Flordaguard' (52 e 30\%, respectivamente) (Tabela 7), e com aplicação de AIB, 'Genovesa' e 'Marianna 2624' (94,75 e 88,50\%, respectivamente) foram superiores a 'Flordaguard' (66,50\%).

Tabela 7. Porcentagem de estacas enraizadas (EE) e número médio de raízes por estaca (RE), em estacas semi-lenhosas tratadas $\left(2000 \mathrm{mg} \mathrm{L}^{-1}\right)$ e não tratadas com ácido indolilbutírico (AIB) de três cultivares de Prunus spp. UFPEL, 2014.

\begin{tabular}{lllll}
\hline \multicolumn{1}{c}{ Porta-enxerto } & \multicolumn{2}{c}{ EE (\%) } & \multicolumn{2}{c}{ RE (N') } \\
\hline & \multicolumn{1}{c}{ Com AIB } & Sem AIB & Com AIB & Sem AIB \\
\hline 'Flordaguard' & $66,50 \mathrm{bA}$ & $30,00 \mathrm{cB}$ & $7,00 \mathrm{bA}$ & $5,50 \mathrm{bA}$ \\
'Genovesa' & $94,75 \mathrm{aA}$ & $52,00 \mathrm{bB}$ & $19,50 \mathrm{aA}$ & $5,50 \mathrm{bB}$ \\
'Marianna 2624' & $88,50 \mathrm{aA}$ & $71,66 \mathrm{aA}$ & $17,00 \mathrm{aA}$ & $10,00 \mathrm{aB}$ \\
\hline Média & 75,41 & 51,22 & 14,50 & 7,00 \\
\hline CV $(\%)$ & & 12,44 & 17,95 \\
\hline
\end{tabular}

Médias seguidas pela mesma letra minúscula na coluna e maiúscula na linha, não diferem entre si pelo teste Tukey $(\mathrm{p}<0,05)$.

Com a aplicação de AIB foi possível obter maior número médio de raízes por estaca de 'Genovesa' e 'Marianna 2624' (19,05 e 17,0, respectivamente), quando comparados aos controles sem AIB (5,50 e 10,0, respectivamente), enquanto que para 'Flordaguard' não 
ocorreu diferença entre o tratamento com e sem a aplicação de AIB (7,0 e 5,5 raízes por estaca, respectivamente) (Tabela 7 ).

Tabela 8. Comprimento médio das três maiores raízes (CMR), porcentagem de estacas vivas (TEV) e porcentagem de estacas brotadas (ECB) em estacas semi-lenhosas tratadas (2000 mg $\mathrm{L}^{-1}$ ) e não tratadas com ácido indolilbutírico (AIB) de três cultivares de Prunus spp. UFPEL, 2014.

\begin{tabular}{lllllll}
\hline Porta-enxerto & \multicolumn{2}{c}{ CMR (cm) } & \multicolumn{2}{c}{ TEV (\%) } & \multicolumn{2}{c}{ ECB (\%) } \\
\hline & Com AIB & Sem AIB & Com AIB & Sem AIB & Com AIB & Sem AIB \\
\hline 'Flordaguard' & $7,00 \mathrm{bA}$ & $5,50 \mathrm{bA}$ & $98,25 \mathrm{aA}$ & $96,75 \mathrm{aA}$ & $40,00 \mathrm{bA}$ & $29,75 \mathrm{cA}$ \\
'Genovesa' & $19,50 \mathrm{aA}$ & $5,50 \mathrm{bB}$ & $97,00 \mathrm{aA}$ & $88,25 \mathrm{bB}$ & $53,25 \mathrm{abA}$ & $50,00 \mathrm{bA}$ \\
'Marianna 2624' & $17,00 \mathrm{aA}$ & $10,00 \mathrm{aB}$ & $99,25 \mathrm{aA}$ & $100,00 \mathrm{aA}$ & $65,00 \mathrm{aB}$ & $78,50 \mathrm{aA}$ \\
\hline Média & 43,50 & 7,00 & 98,16 & 95,00 & 52,75 & 52,75 \\
\hline CV $(\%)$ & \multicolumn{2}{c}{24,44} & \multicolumn{2}{c}{4,58} & & 16,57 \\
\hline
\end{tabular}

Médias seguidas pela mesma letra minúscula na coluna e maiúscula na linha, não diferem entre si pelo teste Tukey $(\mathrm{p}<0,05)$.

O comprimento médio das três maiores raízes foi maior nas estacas de 'Genovesa' e Marianna 2624' tratadas com AIB (19,5 cm e 17,0 cm, respectivamente), em relação ao tratamento controle, e para 'Flordaguard' não houve diferença com o uso de AIB (Tabela 8). Comparando os efeitos da aplicação do AIB, 'Genovesa' e 'Marianna 2624' foram superiores a 'Flordaguard', porém no tratamento controle, 'Genovesa' e 'Flordaguard' não diferiram entre si, mas foram inferiores à 'Marianna 2624' (Tabela 8).

A porcentagem média de estacas vivas foi superior a $98 \%$ e $95 \%$ no tratamento com e sem aplicação de AIB, respectivamente, não havendo diferença entre cultivares no tratamento com AIB, enquanto que no tratamento sem AIB o menor valor foi registrado para a cultivar 'Genovesa' (88,25 \%) em relação a 'Flordaguard' e 'Marianna 2624' (Tabela 8). Para a porcentagem de estacas com brotações, o maior valor foi registrado para 'Marianna 2624' sem aplicação de AIB (78,5\%), com exceção do tratamento com AIB onde 'Marianna 2624' e 'Genovesa' não diferiram (Tabela 8).

Quando analisado apenas o efeito do fator cultivar observamos que a porcentagem de estacas com folhas originais foi maior para 'Marianna 2624', assim como o número de folhas originais por estaca (Tabela 9). 'Flordaguard' apresentou maior comprimento médio das brotações nas estacas (4,62cm) em relação à 'Marianna 2624' e 'Genovesa' (2,87cm e $2,50 \mathrm{~cm}$, respectivamente), que não diferiram entre si (Tabela 9). A maior massa seca das brotações foi apresentada por 'Marianna 2624' (0,87 g). Para a variável massa seca de raízes verificou-se que estacas tratadas com AIB apresentaram média superior de massa seca em relação as não tratadas. Por outro lado, para o fator cultivar não houve diferença entre tratamento, embora 'Flordaguard' e 'Marianna 2624' apresentaram 0,25 g e 'Genovesa' apresentou 0,62 g (Tabela 9).

Cultura Agronômica, Ilha Solteira, v.26, n.2, p.174-190, 2017 
Tabela 9. Número de folhas originais por estaca (NFO), porcentagem de estacas com permanência de folhas (ECF), comprimento médio da maior brotação (CMB), massa seca das brotações (MSB) e massa seca das raízes (MSR) em estacas semi-lenhosas tratadas (2000 mg $\mathrm{L}^{1}$ ) e não tratadas com ácido indolbutírico (AIB) de três cultivars de Prunus spp. UFPEL, 2014.

\begin{tabular}{llllll}
\hline Porta-enxerto & $\mathbf{N F O}\left(\mathbf{n}^{\mathbf{0}}\right)$ & $\mathbf{E C F}(\%)$ & $\mathbf{C M B}(\mathbf{c m})$ & MSB $(\mathbf{g})$ & MSR $(\mathbf{g})$ \\
\hline 'Flordaguard' & $0,00 \mathrm{c}$ & $0,00 \mathrm{c}$ & $4,62 \mathrm{a}$ & $0,12 \mathrm{~b}$ & $0,25^{\mathrm{ns}}$ \\
'Genovesa' & $1,00 \mathrm{~b}$ & $42,37 \mathrm{~b}$ & $2,50 \mathrm{~b}$ & $0,12 \mathrm{~b}$ & 0,62 \\
'Marianna 2624' & $2,00 \mathrm{a}$ & $82,37 \mathrm{a}$ & $2,87 \mathrm{~b}$ & $0,87 \mathrm{a}$ & 0,25 \\
\hline Tratamento & $\mathbf{N F O}\left(\mathbf{n}^{\mathbf{0}}\right)$ & $\mathbf{E C F}(\%)$ & $\mathbf{C M B}(\mathbf{c m})$ & $\mathbf{M S B}(\mathbf{g})$ & MSR $(\mathbf{g})$ \\
\hline Com AIB & $1,16^{\mathrm{ns}}$ & $44,33^{\mathrm{ns}}$ & $3,33^{\mathrm{ns}}$ & $0,33^{\mathrm{ns}}$ & $0,75^{\mathrm{a}}$ \\
Sem AIB & 0,83 & 38,83 & 3,33 & 0,41 & $0,00 \mathrm{~b}$ \\
\hline MÉDIA & 1,00 & 41,53 & 3,33 & 0,37 & 0,37 \\
\hline CV $(\boldsymbol{\%})$ & 40,82 & 41,60 & 20,00 & 24,28 & 42,23 \\
\hline
\end{tabular}

Médias seguidas pela mesma letra, na coluna, não diferem entre si pelo teste Tukey $(\alpha<0,05)$. ns $=$ Não Significativo.

Pela interpretação das análises de macro e micronutrientes verificou-se que no momento em que as amostras de ramos semi-lenhosos foram coletados, $\mathrm{Ca}, \mathrm{Mg}$ e $\mathrm{N}$ estavam em concentrações insuficientes para todas as cultivares (Tabela 5 e 6). Somado à isso, para a cv. Flordaguard, o nutriente $\mathrm{P}$ contidos nos ramos semi-lenhosos apresentou teores abaixo do normal. Para a cv. Genovesa os teores Fe e P também estavam abaixo do normal. Para 'Marianna 2624' o nutriente Fe se encontrava em nível insuficiente e o elemento $\mathrm{Zn}$ apresentava níveis abaixo do normal.

No presente trabalho verificou-se que as taxas de enraizamento, em ambos os experimentos, variaram, principalmente, em função da interação entre os fatores cultivar e AIB, conforme pode ser observado nas Tabelas 1 e 7 , cujos efeitos também foram descritos em vários trabalhos (CHALFUN et al., 2007; CHAGAS et al., 2008; RADMANN et al., 2014). Dentro deste contexto, Canli e Bozkurt (2009) observaram que as taxas de enraizamento de espécies lenhosas são maiores em estacas tratadas com AIB, sendo que com níveis intermediários a altos deste regulador vegetal (entre 1.500 e $2.000 \mathrm{mg} \mathrm{L}^{-1}$ ), o enraizamento é muito mais significativo. Estes mesmos autores obtiveram $75 \%$ de enraizamento de estacas semi-lenhosas de ameixeira 'Sarierik' tratadas com AIB $(2.000 \mathrm{mg}$ $\mathrm{L}^{-1}$ ), valor similar à porcentagem média de enraizamento obtido no presente ensaio para estacas lenhosas $(75,41 \%)$, entretanto, se considerarmos somente as cultivares de ameixeira, os resultados obtidos no presente trabalho são de $21 \%$ e $15,25 \%$ superiores para 'Genovesa' e 'Marianna 2624', respectivamente. Porém, em estacas não tratadas com AIB, a porcentagem de enraizamento foi muito baixa $(10,8 \%)$, valor muito inferior ao obtido no presente trabalho onde a média de enraizamento foi $65,36 \%$ para estacas herbáceas e 51,22\% para semilenhosas. 
Observou-se também que a aplicação de AIB favoreceu o desenvolvimento de raízes, fato evidenciado pelo o número de raízes por estaca (27,30 com AIB e 9,80 sem AIB) e comprimento médio das três maiores raízes (11,96 com AIB e 9,19 sem AIB), cujos resultados encontrados no presente trabalho corroboram àqueles obtidos por Cardoso et al. (2011) com estacas semi-lenhosas de pessegueiro da cultivar Okinawa, onde o tratamento com AIB (2.000 $\mathrm{mg} \mathrm{L}^{-1}$ ) proporcionou maior comprimento e número de raízes por estaca. Aguiar et al. (2005), Mindelo Neto (2006), Canli e Bozkurt (2009) e Sulusoglu e Cavusoglu (2010) também observaram que estacas de Prunus spp. tratadas com AIB tiveram melhor enraizamento do que as não tratadas. Além disso, Aguiar et al. (2005) verificaram que estacas semi-lenhosas do porta-enxerto 'Okinawa' tratadas com $2.000 \mathrm{mg} \mathrm{L}^{-1}$ de AIB tiveram maior produção de massa seca das raízes, fato também observado no presente ensaio.

Tais resultados suportam o fato que a indução e o desenvolvimento das raízes nas estacas dependem da indução da rizogênese, que ocorre pela desdiferenciação celular decorrente dos estímulos promovidos pelas auxinas (POP et al., 2011), e sugerindo que a exposição do câmbio, por meio de lesões laterais, somado ao contato com auxina exógena (AIB), na grande maioria das vezes, promove efeito sinérgico na desdiferenciação celular, favorecendo a indução de formação de raízes e aumentando as taxas de enraizamento de estacas e crescimento de raízes.

No entanto, a eficiência do processo de enraizamento só será efetiva se houver um adequado equilíbrio hormonal endógeno, que pode ser afetado pela concentração exógena de AIB aplicada no tecido vegetal (GONTIJO et al., 2003). De acordo com Pop et al. (2011) a aplicação exógena de auxina em estacas aumenta a sua concentração endógena no tecido, estimulando o início do processo de enraizamento. Isso pode ser evidenciado no trabalho realizado por Sulusoglu e Cavusoglu (2010) com estacas semi-lenhosas de cerejeira (Prunus laurocerasus $L$.) tratadas com seis doses crescentes de AIB, em que as estacas do tratamento controle (sem AIB) tiveram porcentagem de enraizamento abaixo de $50 \%$, enquanto que a aplicação de 2.000 a $4.000 \mathrm{mg} \mathrm{L}^{-1}$ de AIB promoveu de 80 a $100 \%$ de enraizamento, respectivamente, provavelmente por ser a dosagem que proporciona à estaca uma condição adequada para induzir a rizogênese. No entanto, quando aumentaram a dose de AIB para 6.000 e $8.000 \mathrm{mg} \mathrm{L}^{-1}$ a porcentagem de enraizamento não passou dos $30 \%$, significando que a concentração de AIB ultrapassou o limite ótimo do balanço hormonal necessário à indução do enraizamento, tornando-se fitotóxica. Isso pode ocorrer pois, a alta concentração de auxina nos tecidos, induz à biossíntese de etileno, e este atua na regulação da antranilato sintase, enzima que limita a biossíntese de triptofano (precursor da síntese de auxina) (STEPANOVA et al., 2005). Podendo, desta forma, diminuir a disponibilidade da auxina nos tecidos, afetando assim, o desenvolvimento de novas raízes.

Dentre os fatores que podem favorecer a obtenção de uma concentração adequada de auxina na estaca para potencializar o enraizamento está a presença de folhas e brotos nas estacas, que está relacionada com a porcentagem de estacas que se mantém vivas, pois as folhas contribuem significativamente para a síntese de fotoassimilados e em conjunto com as

Cultura Agronômica, Ilha Solteira, v.26, n.2, p.174-190, 2017 
brotações realizam a produção de auxinas, que favorece a diferenciação celular (AGUIAR $e t$ al., 2005). Portanto, para manter o suprimento adequado de carboidratos e hormônios vegetais necessários para formação de raízes é importante manter as folhas na estaca e brotações, bem como a sua funcionalidade, evitando a desidratação (MINDELLO NETO, 2006). No presente trabalho, todas as cultivares mantiveram pelo menos um par de folhas originais, nas estacas herbáceas, o qual corrobora com a relação direta desta característica com a alta porcentagem de enraizamento registrada, mesmo no tratamento sem uso de AIB. A única exceção foi verifica em 'Flordaguard', que mesmo apresentando maior número de folhas originais nas estacas, a média de enraizamento foi inferior comparado às demais cultivares, o qual pode estar relacionado com a menor porcentagem de estacas com brotações em relação as demais cultivares (Tabela 4), uma vez que brotações podem contribuir mais para a síntese de auxina, em função da juvenilidade em relação às folhas originais e mais maduras, fato que pode ter contribuído para a produção diferencial de auxina endógena e para as diferenças nas taxas de enraizamento.

Já para estacas semi-lenhosas, a cv. Flordaguard apresentou menor taxa de brotação e não manteve suas folhas originais, que também foi seguido de porcentagens de enraizamento inferiores às cultivares Marianna 2624 e Genovesa (Tabelas 7 e 8), evidenciando que a manutenção das folhas e/ou presença de brotações na estaca é um fator importante para o enraizamento de estacas. Mindello Neto (2006) destacam que a manutenção das folhas nas estacas, tanto herbáceas quanto semi-lenhosas, é importante para a formação de raízes, independente do tratamento com AIB.

A manutenção das folhas e o equilíbrio hormonal nas estacas são fatores que estão intimamente relacionados com a nutrição mineral das plantas matrizes, pois de acordo com Cunha et al. (2009), a iniciação radicular também é influenciada pelo teor inicial de nutrientes presentes na base da estaca, uma vez que não ocorre mobilização destes nutrientes nesta fase. No entanto, a mobilização durante o crescimento e desenvolvimento da raiz ocorre, principalmente, de forma basípeta a partir dos brotos, sugerindo que a influência da nutrição mineral na iniciação radicular é altamente dependente dos níveis iniciais de nutrientes presentes nos tecidos do órgão submetido ao enraizamento.

No presente trabalho, tanto para as amostras de estacas herbáceas quanto para semilenhosas, os elementos $\mathrm{N}, \mathrm{Ca}$ e $\mathrm{Mg}$ apresentaram teores insuficientes nas três cultivares, desta forma, um possível efeito diferencial dos nutrientes minerais sobre o enraizamento pode estar relacionado aos teores contrastantes de $\mathrm{P}, \mathrm{Fe}$ e $\mathrm{Zn}$, onde para algumas cultivares e/ou época de coleta apresentaram níveis abaixo do normal ou insuficientes (Tabelas 5 e 6).

Nas estacas herbáceas, todas as cultivares apresentaram níveis de Zn abaixo do normal, enquanto 'Marianna 2624' e 'Flordaguard' apresentaram deficiência em Fe. Nas estacas semilenhosas $\mathrm{Zn}$ e Fe foram deficientes para todas as cultivares (Tabela 5). Por outro lado, verificou-se que P estava abaixo do normal em 'Genovesa', nas duas épocas de coleta, sendo esta cultivar a que apresentou o melhor desempenho rizogênico, com os maiores percentuais de enraizamento, número e comprimento de raízes, mesmo sem utilização de AIB. 
Sob condições de deficiência de $\mathrm{P}$ as plantas tendem a realizar realocação de fotoassimilados, visando a otimização bioquímica e fisiológica do elemento presente nos tecidos (HERMANS et al., 2006; YANG et al., 2009; HAMMOND e WHITE, 2011). Quando o $\mathrm{Zn}$ é deficiente, a concentração de proteínas é diminuída e, consequentemente, a de aminoácidos é aumentada (CUNHA et al., 2009). Desta forma, a disponibilidade dos nutrientes $\mathrm{P}$ e $\mathrm{Zn}$ nos tecidos, pode influenciar na indução e formação de raízes laterais, pois o aminoácido triptofano, principal precursor da síntese de auxina, tem sua rota metabólica coordenada pelo Zn (TAIZ; ZEIGER, 2013), assim, a baixa disponibilidade deste elemento mineral pode induzir o aumento das concentrações de triptofano, contribuindo para uma maior síntese de auxina, que associada à realocação de fotoassimilados nos tecidos (promovido pela baixa disponibilidade de $\mathrm{P}$ ), induz à iniciação do enraizamento na base das estacas. Desta forma, destacamos que as estacas herbáceas da cultivar Genovesa, em que os teores de $\mathrm{P}$ e $\mathrm{Zn}$ disponíveis estavam abaixo do normal, apresentaram os melhores resultados relacionados ao percentual de estacas enraizadas e desenvolvimento das raízes (Tabelas 1, 2, 5 e 6).

Em diversas espécies foi demonstrando que a adubação da planta matriz é fator determinante para o sucesso do enraizamento (MALTA et al., 2002; DEL AMOR e MARCELIS, 2005; MONTEGUTI et al., 2008). Albertino et al. (2012) compararam o efeito diferencial sobre o enraizamento e desenvolvimento de estacas de guaranazeiro oriundas de plantas matrizes que receberam adubações anuais, em relação àquelas que não receberam, e verificaram que houve efeito significativo da adubação na porcentagem de estacas enraizadas (68,1\% com adubação), estacas mortas ( $40 \%$ sem adubação) e número de raízes por estaca (11,63 com adubação) de cinco cultivares.

A baixa disponibilidade de Fe tem sido associada a alterações morfológicas nas células epidérmicas da raiz (LÓPEZ-BUCIO et al., 2003), podendo alterar a capacidade rizogênica. No presente trabalho registrou-se deficiência de Fe para a cultivar Mariana 2624 em ambos os estádios de desenvolvimento, e deficiência simultânea de Fe e P para a cultivar Genovesa em estacas coletadas no estádio semi-lenhosas, tendo essas duas cultivares apresentado altos índices de desenvolvimento rizogênico (Tabelas 1, 2 e 7). Tais resultados evidenciam que teores subótimos de $\mathrm{Fe}, \mathrm{P}$ e $\mathrm{Zn}$ podem levar a uma interação benéfica para processo de rizogênese em estacas herbáceas e semilenhosas dos porta-enxertos avaliados, entretanto, é necessário estudos mais aprofundados para comprovar efetivamente tal interação.

Neste contexto, embora não se tenha testado efeito diferencial da nutrição mineral das plantas matrizes, nota-se que a propagação de porta-enxertos pelo método de estaquia está associada à escolha da cultivar a ser propagada, bem como da interação com o fator AIB para se obter uma boa taxa de enraizamento e um bom desenvolvimento da nova planta formada. Os resultados obtidos comprovam que embora o fator genético tenha relevância frente ao enraizamento, uma vez que genótipos de ameixeira apresentam maior capacidade rizogênica nas estacas, o uso do regulador vegetal AIB demonstrou ser responsável pelo aumento significativo na taxa de enraizamento de estacas das cultivares avaliadas.

Cultura Agronômica, Ilha Solteira, v.26, n.2, p.174-190, 2017 
No presente trabalho, muito embora os resultados de enraizamento tenham sido satisfatórios para as três cultivares avaliadas, ainda são necessários estudos complementares para a avaliação do comportamento destes porta-enxertos quanto à adubação diferenciada da planta matriz, à capacidade de aclimatação pós-enraizamento e desenvolvimento da muda no campo.

\section{CONCLUSÃO}

A propagação dos porta-enxertos 'Flordaguard', 'Genovesa' e 'Marianna 2624' por estaquia herbácea e semi-lenhosa é viável com a utilização de solução de AIB em concentração de $2.000 \mathrm{mg} \mathrm{L}^{-1}$.

O fator genético é determinante nas taxas de enraizamento e a cultivar Genovesa apresentou as maiores porcentagens de enraizamento e qualidade de raízes, tanto com ramos herbáceos como semi-lenhosos especialmente quando tratadas com AIB.

A composição mineral dos tecidos das estacas demonstra ter influência no enraizamento, destacando-se a associação entre os níveis de elementos minerais como o Fe e P.

\section{AGRADECIMENTOS}

À CAPES pela concessão de bolsa de estudos, à EMBRAPA Clima Temperado pelo local dos experimentos.

\section{REFERÊNCIAS BIBLIOGRÁFICAS}

AGUIAR, R. S.; SANTOS, C. E.; ZIETEMANN, C.; ASSIS, A. M.; MORAIS, V. J.; ROBERTO, S. R. Enraizamento de estacas semi-lenhosas do pessegueiro 'Okinawa' submetidas a diferentes dosagens de ácido indolbutírico. Acta Scientiarum Agronomy, Maringá, v. 27, n. 3, p.461-466, 2005.

ALBERTINO, S. M. F.; NASCIMENTO FILHO, F. J.; SILVA, J. F.; ATROCH, A. L.; GALVÃO, A. K. L. Enraizamento de estacas de cultivares de guaranazeiro com adubação de plantas matrizes. Pesquisa Agropecuária Brasileira, Brasília, v. 47, n. 10, p.1449-1454, 2012.

ALCANTARA, G. B.; OLIVEIRA, Y.; LIMA, D. M.; FOGAÇA, L. A.; PINTO, F.; BIASI, L. A. Efeito dos ácidos naftaleno acético e indolilbutírico no enraizamento de estacas de jambolão [Syzygium cumini (L.) Skeels]. Revista Brasileira de Plantas Medicinais. Botucatu, v. 12, n. 3, p.317-321, 2010. 
CANLI, F. A.; BOZKURT, S. Effects of Indolebutyric Acid on Adventitious Root Formation from semi-hardwood cuttings of ' Sarierik' plum. Journal of Applied Biological Sciences, Turkey, v. 3, n. 1, p. 45-48, 2009.

CARDOSO, C; YAMAMOTO, L. Y.; PRETI, E. A.; ASSIS, A. M.; NEVES, C. S. V. J.; ROBERTO, S. R. AIB e substratos no enraizamento de estacas de pessegueiro 'Okinawa' coletadas no outono. Semina: Ciências Agrárias, Londrina, v. 32, n. 4, p.1307-1314, 2011.

CHAGAS, E. A.; PIO, R.; BETTIOL NETO, J. E.; SOBIERAJSKI, G. R.; DALL'ORTO, F. A. C.; SIGNORINI, G. Enraizamento de estacas lenhosas de pessegueiro e clones de umezeiros submetidos a aplicação de AIB. Ciências agrotecnológicas, Lavras, v. 32, n. 3, p.986-991, 2008.

CHALFUN, N. N. J.; PIO, R.; ROSSI, C. J. A.; HYUJI, H. C.; ABRAHÃO, E.; ALVARENGA, A. A.; ALVES, E. C. Enraizamento de estacas dos marmeleiros 'Japonês' e 'Portugal' em diferentes substratos e concentrações de ácido indolbutírico. Revista Ceres, Viçosa, v. 54, n. 311, p.68-72, 2007.

COMISSÃO DE QUÍMICA E FERTILIDADE DO SOLO - RS/SC. Manual de adubação e calagem para os Estados do Rio Grande do Sul e de Santa Catarina. 11. ed. Santa Maria, RS: SBCS Núcleo Regional Sul, 2016. 375 p.

CUNHA, A. C. M. C. M.; PAIVA, H. N.; XAVIER, A. OTONI, W. C. Papel da nutrição mineral na formação de raizes advenicias em plantas lenhosas. Pesquisa Florestal Brasileira, Colombo, v. 1, n. 58, p.35-47, 2009.

DEL AMOR, F. M.; MARCELIS, L. F. M. Response of Plant Growth to Low Calcium Concentration in the Nutrient Solution. Acta Horticulturae, Leuven, v. 1, n. 3 , p.529-533, 2005 .

DUVAL, H.; HOERTER, M.; POLIDORI, J.; CONFOLENT, C.; MASSE, M.; MORETTI, M.; VAN GHELDER, C.; ESMENJAUD, D. High-resolution mapping of the RMia gene for resistance to root-knot nematodes in peach. Tree Genetics \& Genomes, Gewerbestrasse, v. 35, n. 10, p.297-306, 2013.

FERREIRA, D.F. SISVAR: um programa para análises e ensino de estatística. Revista Symposium, Lavras, v. 6, n. 2, p.36-41, 2008.

FRANZON, R. C.; CARPENEDO, S.; SILVA, J. C. S. Produção de mudas: principais técnicas utilizadas na propagação de fruteiras. Brasília: EMBRAPA Cerrados, 2010. 54 p. (documento 283).

GONDIM, T. M. S.; MARIA, J.; SEDIYAMA, T. Anatomia das raízes adventícias em estacas de macadâmia. Agropecuária Técnica, Areia, v. 20, n. 2, p.45-51, 1999.

GONTIJO, T. C. A.; RAMOS, J. D.; MENDONÇA, V.; PIO, R.; ARAÚJO NETO, S. E.; CORREAA, F. L. O. Enraizamento de diferentes tipos de estacas de aceroleira utilizando ácido indolbutírico. Revista Brasileira de Fruticultura, Jaboticabal, v. 25, n. 2, p.290-292, 2003.

Cultura Agronômica, Ilha Solteira, v.26, n.2, p.174-190, 2017 
HAMMOND, J. P.; WHITE, P. J. Sugar Signaling in Root Responses to Low Phosphorus Availability. Plant Physiology, Rockville, v. 156, n. 3, p.1033-1040, 2011.

HERMANS, C.; HAMMON, J. P.; WHITE, P. J.; VERBRUGGEN, N. How do plants respond to nutrient shortage by biomass allocation? Trends in Plant Science, Philadelphia, v. 11, n. 12, p.610-617, 2006.

LOPEZ-BUCIO, J.; CRUZ-RAMIREZ, A.; LUIS HERRERA-ESTRELLA, L. The role of nutrient availability in regulating root architecture. Current Opinion in Plant Biology, Amsterdam, v. 6, n. 5, p.280-287, 2003.

MALTA, M. R.; FURTINI NETO, A. E.; ALVES, J. D.; GUIMARAES, P. T. G. Efeito da aplicação de zinco via foliar na síntese de triptofano, aminoácido e proteínas solúveis em mudas de cafeeiro. Brazilian Journal of Plant Physiology, Lavras, v. 14, n. 1, p.31-37, 2002.

MINDELO NETO, U. R. Estaquia herbácea de pessegueiro cv. 'Charme', em função de diferentes concentrações de ácido indolbutírico (AIB) e número de folhas. Revista Brasileira de Agrociência, Pelotas, v. 12, n. 1, p.27-29, 2006.

MONTEGUTI, D., BIASI, L. A., PERESUTI, R. A., SACHI, A. T., OlIVEIRA, O. R., SKALITZ, R. Enraizamento de estacas lenhosas de porta-enxertos de videira com uso de fertilizante orgânico. Scientia Agraria, Piracicaba, v. 5 n. 9, p.99-103, 2008.

NICOLOSO, F. T.; FORTUNATO, R. P.; FOGAÇA, M. A. F. Influencia da posição da estaca no ramo sobre o enraizamento de Pfaffia glomerata(Spreng.) Pedersen em dois substratos. Ciência Rural, Santa Maria, v. 29, n. 2, p.277-283, 1999.

POP, T. I.; PAMFIL, D.; BELLINI, C. Auxin control in the formation of adventitious roots. Notulae Botanicae Horti Agrobotanica Cluj-Napoca, Cluj-Napoca, v. 36, n. 1, p.307-316, 2011.

RADMANN, E. B.; BIANCHI, V. J.; OLIVEIRA, R. P.; FACHINELLO, J. C. Multiplicação in vitro e alongamento das brotações micropropagadas do porta-enxerto 'Tsukuba 1' (Prunus persica L.). Revista Brasileira de Fruticultura, Jaboticabal, v. 31, n. 3, p.656-663, 2009.

RADMANN, E. B.; FEIJO, A. R.; GOULART, R. C.; FISCHER, D. L. O.; BIANCHI, V. J. Interação entre o genótipo e AIB no enraizamento de estacas semilenhosas de porta-enxertos de pessegueiro. Nativa Pesquisas Agrárias e Ambientais, v. 2, n. 4, p.129-133, 2014.

RODRIGUES, A. C.; SILVEIRA, C. A. P.; FORTES, G. R. L.; FACHINELlO, J. C.; SILVA, J. B. Estabelecimento e multiplicação in vitro de Prunus sp. em diferentes meios de cultura. Revista Brasileira de Fruticultura, Jaboticabal, v. 25, n. 1, p.131-133, 2003.

SCHIMITZ, J. D.; BIANCHI, V. J.; PASA, M. S.; KULKAMP, A. L.; FACHINELLO, J. C. Vigor e produtividade do pessegueiro 'Chimarrita' sobre diferentes porta-enxertos. Revista Brasileira de Agrociência, Pelotas, v. 18, n. 4, p.01-10, 2012.

Cultura Agronômica, Ilha Solteira, v.26, n.2, p.174-190, 2017 
STEPANOVA, A. N.; HOYT, J. M.; HAMILTON, A. A.; ALONSO, J. M. A link between ethylene and auxin uncovered by the characterization of two root-specific ethylene-insensitive mutants in Arabidopsis. Plant Cell, Rockville, v. 17, n. 8, p.2230-2242, 2005.

SUlUSOGLU, M.; CAVUSOGLU, A. Vegetative propagation of Cherry laurei (Prunus laurocerasus L.) using semi-hardwood cuttings. African journal of Agricultural Research, Victoria Island, v. 5, n. 23, p.3196-3202, 2010.

TAIZ, L.; ZEIGER E. Fisiologia Vegetal. 5 ${ }^{\mathrm{a}}$ ed. Porto Alegre: Artmed, 2013. 918 p.

TOFANELli, M. B. D.; CHALFUN, N. N. J.; HOFFMANN, A.; JUNIO, A. C. Efeito do ácido indolbutírico no enraizamento de ramos semilenhosos de pessegueiro. Pesquisa Agropecuária Brasileira, Brasília, v. 27, n. 7, p.939-944, 2002.

YANG, J; ZHU, Z.; GERENDÁS, J. Interactive effects of phosphorus supply and light intensity on glucosinolates in pakchoi (Brassica campestris L. ssp. chinensis var. communis). Plant and Soil, Pretoria, v. 333, n. 2, p.323-333, 2009. 